\title{
RE-LAYOUT FASILITAS PRODUKSI DENGAN METODE LINE BALANCING UNTUK MENINGKATKAN PRODUKTIVITAS DI PT. KMK GLOBAL SPORTS
}

\author{
Dede Rosita $^{1)}$ Marjuki Zulziar $^{2)}$, Rini Alfatiyah ${ }^{3)}$, Edi Supriyadi' ${ }^{4}$, Muhammad Shobur ${ }^{5)}$, \\ 1) Mahasiswa Program Studi Teknik Industri Universitas Pamulang \\ 2) Dosen Program Studi Teknik Industri Universitas Pamulang \\ dosen00347@unpam.ac.id, shobur.muhammed@gmail.com,dosen00905@unpam.ac.id, dosen01775@unpam.ac.id
}

\begin{abstract}
ABSTRAK
PT. KMK Global Sports merupakan perusahaan yang bergerak diindustri pembuatan sepatu, terutama sepatu bermerk Nike. Salah satu produk hasil produksinya adalah Nike Tanjun. Permasalahan yang dihadapi adalah penumpukan barang (bottleneck) yang terjadi di area proses prestitching dan stitching. Penumpukan tersebut dikarenakan ada beberapa stasiun kerja yang mengalami waktu lebih yang disebab kan aliran proses tidak sesuai serta tidak meratanya beban kerja antar stasiun. Dampak yang dialami perusahaan adalah tidak tercapainya target atau output produksi Seperti produk sepatu Nike Tanjun ini memiliki target produksi 220 pasang/ jam sedangkan aktualnya hanya 170 pasang /jam .Oleh karena itu penulis mengusulkan perlu adanaya perubahan aliran proses antar stasiun kerja dengan cara merubah layout sekarang dengan layout baru, serta perlu diterapkan keseimbangan lini (line balancing) diarea prestitching dan stitching, dengan tujuan untuk meningkatkan produktivitas di line Y10 serta membuatkan lembar standa kerja untuk setiap proses dan setiap stasiun kerja. Dari perhitungan line balancing usulan perbaikan ini menghasilkan jumlah stasiun kerja berkurang, meningkatkan efisiensi yang tinggi dan waktu tuggu yang minimum serta meningkatnya produktivitas dari yang 170 pasang/jam menjadi 218 pasang/ jam. Untuk lini produksi line Y10 yang awalnya terdapat 141 stasiun kerja berubah menjadi 131 stasiun kerja, total waktu kerja yang awalnya sebesar 41.02 detik berkurang menjadi 37.64 detik. Berdasarkan pengolahan data tersebut dapat diketahui bahwa dengan diterapkan metode Line Balancing perusahaan mampu melakukan improvment sehingga hasilnya mengurangi lead time mengurangi penumpukan barang (bottleneck), membuat beban kerja yang merata, serta meningkatkan produktivitas karyawan, khususnya pada line Y10 Nike Tanjun.
\end{abstract}

Kata Kunci: Relayout,Line Balancing, Produktivitas.

\section{PENDAHULUAN}

Persaingan bisnis yang semakin ketat diera globalisasi ini menuntut perusahaan untuk menyusun kembali strategi dan taktik bisnisnya sehari-hari. Esensi dari persaingan terletak pada bagaimana perusahaan mengimplementasikan proses dalam menghasilkan produk atau jasa yang lebih baik, lebih murahdan cepat dibandingkanpesaingnya. Perancangan fasilitas produksi sangat berpengaruh pada kinerja suatu perusahaan, hal ini yang menyebabkan keterlambatan penyelesaian produk dan menambah biaya produksi di akibat kan kurang baik nya perpindahan bahan, produk, peralatan, tenaga kerja dan informasi serta tata letak yang kurang baik pula. Pemanfaatan area dalam pengaturan tata letak fasilitas merupakan hal utama dalam perancangan tata letak industri manufaktur

PT. KMK Global Sports adalah salah satu perusahaan manufaktur yang bergerak di bidang produksi sepatu Nike. Terdapat pemborosan Matrial Handling dalam proses produksi, hal ini disebabkan karena tata letak fasilitas tidak sesuai dengan dengan jarak antara stasiun kerja satu ke stasiun berikut nya. Aliran bahan yang tidak tertata rapih menyebabkan kemacetan pada aliran perpindahan bahan, dan jarak antar stasiun kerja tidak efektif dan efisien. Sehingga hasil output kurang maksimal. Selain itu juga dapat mengakibatkan biaya produksi menjadi meningkat, adapun data hasil produktivitas yang dihasilkan selama tiga bulan

\begin{tabular}{|c|c|c|c|c|}
\hline \multirow[t]{2}{*}{ BCLAV } & \multicolumn{2}{|c|}{$\begin{array}{l}\text { ACCTMULASI } \\
\text { PRODTCTIOY }\end{array}$} & \multirow[t]{2}{*}{96} & \multirow[t]{2}{*}{ Babuce } \\
\hline & PLAN & ACTLAL & & \\
\hline Desember 18 & 26.400 pairs & 13.440 pairs & $51 \%$ & -12960 \\
\hline Januari' 19 & 38.720 pairs & 26. 400 pairs & $68 \%$ & -12320 \\
\hline Februari'19 & 38.720 pairs & 27.200 pairs & $70 \%$ & -11.520 \\
\hline TOTAL & 103.840 & 67.040 & $65 \%$ & -36.800 \\
\hline
\end{tabular}

bias dilihat pada Tabel 1.1 
Tabel 1.1 Akumulasi Produksi PT. KMK Global Sports

(Sumber : PT. KMK Global Sports)

Berdasarkan latar belakang penelitian diatas, maka penelitian akan dilakukan re-layout fasilitas produksi dengan metode line balancing untuk meningkatkan produktivitas di pt. kmk global sports

\section{DASAR TEORI}

\section{A. Tata Letak Fasilitas Produksi atau Layout}

Tata desain pabrik, desain tata letak, membuat konsep, serta membuat sistem pembuatan barang atau jasa, desain ini menggambarkan desain lantai, dalam satu susunan fasilitas fisik (perlengkapan, tanah, gedung dan fasilitas lain) guna menunjang kelancaran proses produksi. Tata letak pabrik memiliki dampak yang signifikan terhadap performansi perusahaan seperti ongkos, material handling, work in process, inventory, lead time, produktivitas, dan performasi pengantaran. Desain fasilitas pabrik yang baik yang mampu meningktakan keefektifan dan keefisienan melalui penurunan perpindahan jarak material dan ongkos material handling.

\section{B. Pengertian Layout}

Menurut Apple, James M. (1990), tata letak fasilitas adalah fungsi yang melibatkan analisa, perencanaan dan desain dari interelasi antara pengaturan fasilitas fisik, pergerakan material, aktivitas yang dihubungkan dengan personil dan aliran informasi yang dibutuhkan untuk mencapai performansi optimum dalam rentang aktivitas yang berhubungan. Menurut Wignjosoebroto (1996), Tata letak pabrik (plant layout) atau letak fasilitas (facilities layout) pada dasarnya dapat didefinisikan sebagai suatu cara pengaturan fasilitas-fasilitas untuk menunjang kelancaran proses produksi.

\section{Pengertian Produktivitas}

Secara umum produktivitas mengandung pengertian yaitu perbandingan antara hasil yang dicapai atau output dengan Berdasarkan latar belakang penelitian diatas, maka dapat dibuat perumusan masalah dari penelitian ini sebagai berikut:

1. Bagaimanakualitaspelayananjasaperpanjanga nbuku uji berkala di DinasPerhubungan Kota Tangerang Selatan?

2. BagaimanahasilaplikasimetodeServqual, IPA dan Fishbone Chartgunamenurunkankeluhankonsumenjasa perpanjanganbuku uji berkala diDinasPerhubungan Kota Tangerag Selatan?

keseluruhan sumber daya yang digunakan atau input (Sedarmayanti, 2009). Pengertian produktivitas secara teknis adalah mengefisiensikan produksi terutama dalam penerapan ilmu dibidang teknologi kedalam suatu sistem industri. Sedangkan pengertian produktivitas secara finansial adalah pengukuran produktivitas secara input dan output yang telah dikualifikasikan.

Jenis-jenis produktivitas anatara lain sebagai berikut:

1. Produktivitas Parsial

2. Produktivitas Total

\section{Teknik Pengukuran Kerja}

Menurut Sedarmayanti (2009:87),Teknik pengukuran kerja dapat dilaksanakan antara lain dengan cara sebagai berikut:

1. Meneliti waktu;

2. Mengambil contoh kegiatan dan tindak lanjutnya, serta contoh tingkat kegiataanya;

3. Membuat sintesa dan keterangan standar;

4. Menetapkan sistem waktu gerak;

5. Mengadakan perkiraan analitis;

6. Mengadalkan perkiraan perbandingan.

\section{E. Metode Line Balancing}

Line balancing merupakan metode penugasan sejumlah pekerjaan ke dalam stasiunstasiun kerja yang saling berkaitan/berhubungan dalam suatu lintasan atau lini produksi sehingga setiap stasiun kerja memiliki waktu yang tidak melebihi waktu siklus dari stasiun kerja tersebut.

Menurut Gaspersz (2001) dalam Dian Suci Lestari (2016:18), line balancing merupakan penyeimbangan penugasan elemenelemen tugas dari suatu assembly line ke work stations untuk meminimumkan banyaknya work station dan meminimumkan total harga idle time pada semua stasiun untuk tingkat output tertentu, 
yang dalam penyeimbangan tugas ini, kebutuhan waktu per unit produk yang dispesifikasikan untuk setiap tugas dan hubungan sekuensial harus dipertimbangkan. Tujuan line balancing adalah untuk memperoleh suatu arus produksi yang lancar dalam rangka memperoleh utilisasi yang tinggi atas fasilitas, tenaga kerja, dan peralatan melalui penyeimbangan waktu kerja antar work station. Persyaratan umum yang harus digunakan dalam suatu keseimbangan lintasan produksi adalah dengan meminimumkan waktu menganggur (idle time) dan meminimumkan pula keseimbangan waktu senggang (balance delay). Sedangkan tujuan dari lintasan produksi yang seimbang adalah sebagai berikut:

1. Menyeimbangkan beban kerja yang dialokasikan pada setiap workstation sehingga setiap workstation selesai pada waktu yang seimbang dan mencegah terjadinya bottleneck. Bottleneck adalah suatu operasi yang membatasi output dan frekuensi produksi;

2. Menjaga agar pelintasan perakitan tetap lancar;

3. Meningkatkan efisiensi atau produktifitas.

Menurut standar dari Nike untuk perhitungan line Balancing adalah sebagai berikut:

$$
L O B=\frac{\text { Lead Time }}{\text { Actual Number Of Work Station } \times \text { Takt Time }} \times 100 \%
$$

Ideal Operator adalah jumlah operator atau karyawan yang dibutuhkan dalam setiap proses, adapun rumus ideal operator sebagai berikut:

$$
\text { Ideal Operator }=\frac{\text { Cycle Time }+10 \% \text { Allowance }}{\text { Takt Time }}
$$

Standar Time Operator adalah waktu standar dari setiap proses dari masing-masing operator atau team member. Adapun rumusnya adalah sebagai berikut:

Standar Time $=\frac{\text { Jumlah Cycle Time }+10 \% \text { Allowance }}{\text { Proposed Operator }}$

Balancing Factor adalah faktor keseimbangan beban kerja dari setiap stasiun kerja. Adapun rumusnya adalah sebagai berikut:
Balancing Factor $=\frac{\text { Standar } \text { Time/Operator }}{\text { Takt Time }}$

\section{METODOLOGI PENELITIAN}

\section{A. Lokasi Penelitian}

Untuk memfokuskan kegiatan penelitian yang dilakukan, maka ruang lingkup penelitian dibatasi berdasarkan tempat penelitian. Tempat penelitian ini dilakukan di PT. KMK GLOBAL SPORTS Jl. Cikupa Mas Raya, Kawasan Industri No.17 Cikupa Tangerang, Banten.

\section{B. Jenis Penelitian}

Jenis penelitian yang dilakukan dalam penelitian ini adalah penelitian deskriptif. Penelitian deskriptif adalah suatu penelitian yang dilakukan dengan tujuan utama unuk memberikan gambaran atau deskripsi tentang suatu keadaan secara objektif. Desain penelitian ini digunakan untuk memecahkan masalah yang sedang dihadapi pada situasi sekarang.

\section{Data Dan Sumber Data}

Jenis dan sumber data yang digunakan dalam penelitian ini adalah:

1.Data Primer

Data primer merupakan data yang diperoleh secara langsung dari PT. KMK Global Sports yang dilakukan pengolahan data kembali. Data primer yang digunakan dalam penelitian ini diperoleh dengan cara pengamatan langsung, wawancara kepada staff yang berkaitan dengan tata letak fasilitas produski serta produktivitas.

2.Data Sekunder

Data sekunder merupakan data yang diperoleh peneliti dengan cara melakukan kajian pustaka berdasarkan sumber-sumber tertentu, seperti buku, skripsi, jurnal-jurnal ilmiah untuk dibandingkan dengan kondisi aktual di PT.KMK Global Sports, untuk selanjutnya dilakukan pengolahan data agar permasalahan yang sedang dihadapi dapat diselesaikan. Adapun data sekunder yang digunakan dalam penelitian ini antara lain:

a. Data permintaan/order selama satu tahun.

b.Data hasil output selama satu tahun. 


\section{Metode Pengumpulan Data}

Teknik pengumpulan data yang dilakukan dalam penelitian ini adalah:

1.Survey dan Observasi;

2.Wawancara dan Diskusi;

3.Dokumentasi;

4. Studi Pustaka;

\section{E. Definisi Operasional Variabel}

Variabelpenelitianadalahsegalasesuatu yang berbentukapasaja yang ditetapkan oleh penilitiuntukdipelajarisehinggadiperolehinforma sitentanghaltersebut,

kemudianditarikkesimpulannya (Sugyono, 2016:38). Variabel dalam penelitian ini terbagi menjadi dua yaitu variabel $\mathrm{X}$ dan Y.Operasionalvariabeldiperlukangunamenentuk anjenisdalamindikatordarivariabel-variabel yang terkaitdalampenelitianini.

Secaralebihrincioperasionalisasivariabeldalampe nelitianinidapatdilihat pada Tabel 3.1

Tabel 3.1 Operasional Variabel

\begin{tabular}{|l|l|}
\hline \multicolumn{1}{|c|}{ Konsep Variabel } & \multicolumn{1}{|c|}{ Indikator } \\
\hline Aliran Proses dan Line Balancing (X) & \begin{tabular}{l} 
1. \\
Proses mengikuti SOP (Standard \\
Pemerataan Operasional \\
\multicolumn{1}{|c|}{ Prosedur) }
\end{tabular} \\
& $\begin{array}{l}\text { 2. Jarak standar antar proses } \\
\text { 3. Waktu siklus kerja per proses } \\
\text { 4. Total waktu untuk 1 pasang } \\
\text { sepatu }\end{array}$ \\
\hline Produktivitas (Y) & 5. beban kerja \\
\hline & $\begin{array}{l}\text { 1. Efektivitas pekerja } \\
\text { 2. Efisiensi } \\
\text { 3. Improvment }\end{array}$ \\
\hline
\end{tabular}

(Sumber: Pengolahan Data Sendiri Dari Berbagai Sumber).

\section{Hasil dan Pembahasan}

\section{A. Layout Awal Plant D5}

Sebelum melakukan proses Re-layout pada lantai produksi yang terdapat di gedung D5 line $\mathrm{Y} 10$, penulis meneliti dan melakukan pengamatan layout dan line balancingpada line tersebut.

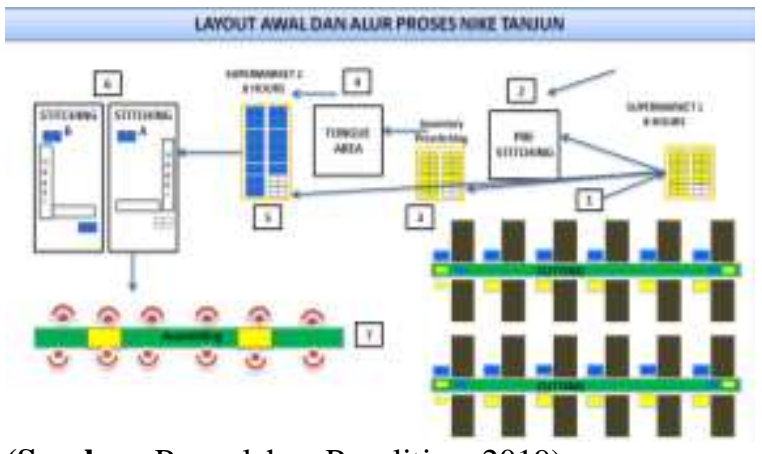

(Sumber: Pengolahan Penelitian, 2019)

Gambar 4.1Layout Awal Proses Nike Tanjun

Pada layout diatas terdapat permasalahan bahwa aliran proses dan aliran bahan jaraknya terlalu jauh, sehingga ada beberapa proses yang harus mengambil komponen dengan jarak yang lumayan jauh. sehingga menyebab kan waktu tunggu untuk proses selanjut nya lebih lama, dan juga banyak memerlukan menpower untuk mengantar barang atau bahan baku.

\section{B. Kapasitas Produksi}

Kapasitas produksi adalah penetapan target untuk menentukan berapa banyak produk yang harus tercapai produksi selama masa tertentu. Kapasitas produksi terbagi menjadi dua yaitu kapasitas terpasang dan kapasitas aktual. PT.KMK Global Sports memiliki kapasitas terpasang atau target produksi yang dapat dilihat pada Tabel 4.2.

Tabel 4.2Plann Production Y10

\begin{tabular}{|c|c|l|}
\hline \multirow{2}{*}{ Item } & \multicolumn{1}{|c|}{$\begin{array}{c}\text { Satuan } \\
\text { (pasang) }\end{array}$} & \multicolumn{1}{|c|}{ Keterangan } \\
\hline \multirow{4}{*}{ Plann Production } & 38.720 & Pasang/Bulan \\
\cline { 2 - 3 } & 8.800 & Pasang/Minggu \\
\cline { 2 - 3 } & 1.760 & Pasang/Hari \\
\cline { 2 - 3 } & 220 & Pasang/Jam \\
\hline \multirow{3}{*}{$\begin{array}{c}\text { Plann Production } \\
\text { Stitching }\end{array}$} & 19.360 & Pasang/Bulan \\
\cline { 2 - 3 } & 4.400 & Pasang/Minggu \\
\cline { 2 - 3 } & 880 & Pasang/Hari \\
\cline { 2 - 3 } & 110 & Pasang/Jam \\
\hline
\end{tabular}

(Sumber: PT. KMK Global Sports, 2019)

Berdasarkan tabel tersebut diketahui bahwa kapasitas produksi atau plann production perusahaan sebesar 1.760 pairs/days dengan jam kerja 8 jam atau 220 pairs/jam. Akan tetapi akual produktivitas di lini produksi sangat jauh dari planning production atau target yang sudah 
ditentukan. Output aktual produksi dapat dilihat pada Tabel 4.3.

Tabel 4.3 Akumulasi Produksi

\begin{tabular}{|c|c|c|c|c|}
\hline \multirow{2}{*}{ BULAN } & \multicolumn{2}{|c|}{$\begin{array}{c}\text { ACCUMULASI } \\
\text { PRODUCTION }\end{array}$} & \multirow{2}{*}{$\%$} & \multirow{2}{*}{ Balance } \\
\cline { 2 - 3 } & PLAN & ACTUAL & & \\
\hline \multirow{2}{*}{ Desember'18 } & 26.400 & 13.440 & $51 \%$ & -12.960 \\
\hline Januari'19 & 38.720 & 26.400 & $68 \%$ & -12.320 \\
\hline Februari'19 & 38.720 & 27.200 & $70 \%$ & -11.520 \\
\hline T0TAL & 103.840 & $\mathbf{6 7 . 0 4 0}$ & $\mathbf{6 5 \%}$ & $\mathbf{- 3 6 . 8 0 0}$ \\
\hline
\end{tabular}

(Sumber: PT. KMK Global Sports,2019)

Dari tabel diatas dapat dilihat pada bulan pertama jalan produksi y10 hanya mampu menghasilkan $51 \%$ dari target yang ditentukan, sedangkan pada bulan kedua hanya mampu menghasilkan $68 \%$, dan pada bulan ketiga hanya mampu menghasikan $70 \%$. Jadi rata-rata dalam tiga bulan jalan produksi mereka hanya mampu menghasilkan sebesar 65\% atau sebanyak 67.040 pasang sepatu.

\section{Waktu Siklus dan Waktu Baku}

Waktu siklus adalah waktu yang dibutuhkan pekerja untuk menyelesaikan satu proses operasi . waktu siklus untuk setiap stasiun kerja di perusahaan didapatkan dari pengukuran langsung dengan menggunakan stop watchsebanyak 5 kali pengamatan atau lebih. Waktu standar adalah waktu yang sudah ditentukan oleh perusahaan untuk setiap proses produksi, setiap produk yang diproduksi memiliki waktu baku yang berbeda-beda sesuai target yang ditentukan. Untuk pengamatan waktu baku area prefit dapat dilihat pada Tabel 4.4

Tabel 4.4 Pengamtan Waktu Siklus Area Prefit

\begin{tabular}{|c|c|c|c|c|c|c|c|c|c|}
\hline № & DESCRPPTIONPROCESS & Takt Time & Equipment & $\begin{array}{c}\text { CT } \\
\text { Average }\end{array}$ & $\begin{array}{l}\text { CT }+10 \% \\
\text { Allowance }\end{array}$ & $\begin{array}{c}\text { Operator yang } \\
\text { dibutuhkan }\end{array}$ & $\begin{array}{l}\text { Standar } \\
\text { Operator }\end{array}$ & $\begin{array}{l}\text { Standar } \\
\text { Time//op }\end{array}$ & $B F \%$ \\
\hline A & Screen print & & & & & & & & \\
\hline 1 & Vamp & 16,36 & Manal & 15,80 & 17,38 & 1,06 & 1,00 & 17,38 & $106 \%$ \\
\hline 2 & Qirilo & 16,36 & Manal & 15,99 & 17,59 & 1,07 & 1,00 & 17,59 & $107 \%$ \\
\hline 3 & Tongale & 16,36 & Manal & 12,70 & 13,97 & 0,85 & 1,00 & 1397 & $85 \%$ \\
\hline в & Reifforement & & & & & & & & \\
\hline 1 & Cenenringry and ataching collar reinf & 16,36 & Manal & 24,64 & 27,10 & 1,66 & 2,00 & 13,55 & $83 \%$ \\
\hline c & Stiching process in quarter area & & & & & 0,00 & & & \\
\hline 1 & Stitching close seam Quarter in'out Ist & 16,36 & Manal & 14,32 & 15,75 & 0.96 & 1,00 & 15,75 & $96 \%$ \\
\hline 2 & Hammering after seam & 16,36 & Hanmering & 15,51 & 17,06 & 1,04 & 1,00 & 17,06 & $104 \%$ \\
\hline D & Sitithing Process & & & & & & & & \\
\hline 1 & Atching yesctay to pallet & 16,36 & Manal & 31,57 & 34,73 & 2,12 & 2,00 & 17,36 & $106 \%$ \\
\hline 2 & Attaching quarter to pallet & 16,36 & Manal & 31,47 & 34,62 & 2,12 & 2,00 & 17,31 & $106 \%$ \\
\hline 3 & Sitching perstay & 16,36 & Brodeter $342 \mathrm{H}$ & 32,68 & 35,95 & 2,20 & 2,00 & 17,98 & $110 \%$ \\
\hline E & Skiving Collar Foam & 16,36 & Shiving Foam & 10,85 & 11,94 & 0,73 & 1,00 & 11,94 & $73 \%$ \\
\hline & TOTAL & & & & 226,18 & & 14 & & \\
\hline
\end{tabular}

(Sumber: Pengolahan Penelitian, 2019)

Berdasarkan tabel waktu siklus tersebut didapat bahwa yang memiliki nilai tertinggi yaitu pada proses stitching eyestay sebesar 35.18 detik, sedangkan proses yang memiliki nilai terendah adalah proses skiving collar foam sebesar 11.94 detik, dengan total waktu proses keseluruhan sebesar 226.08 detik atau sekitar 3.77 menit ,dengan total 14 operator. Adapun Grafiknya bisa dilihat dibawah ini:

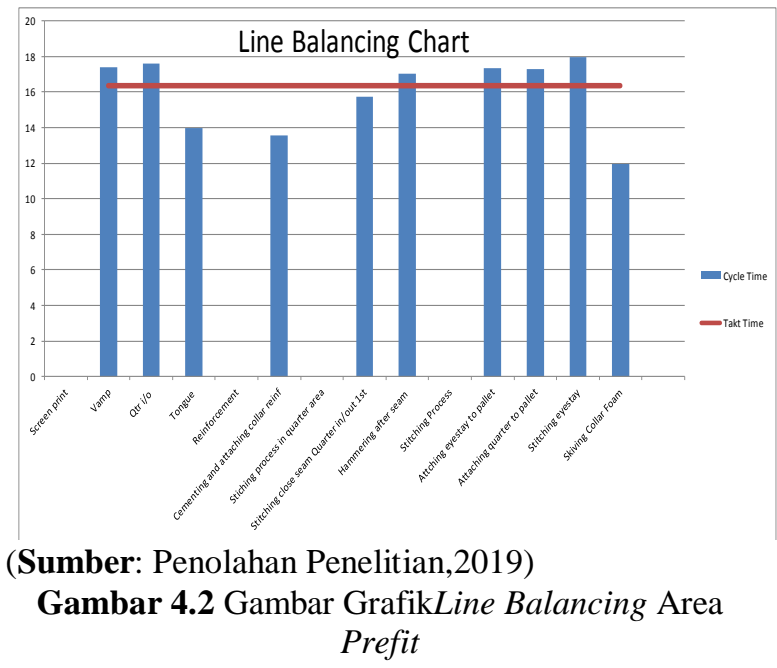

Untuk pengamatn waktu siklus area stitching di lihat pada Tabel 4.5

Tabel 4.5 Pengamatan Waktu Siklus Area Stitching 


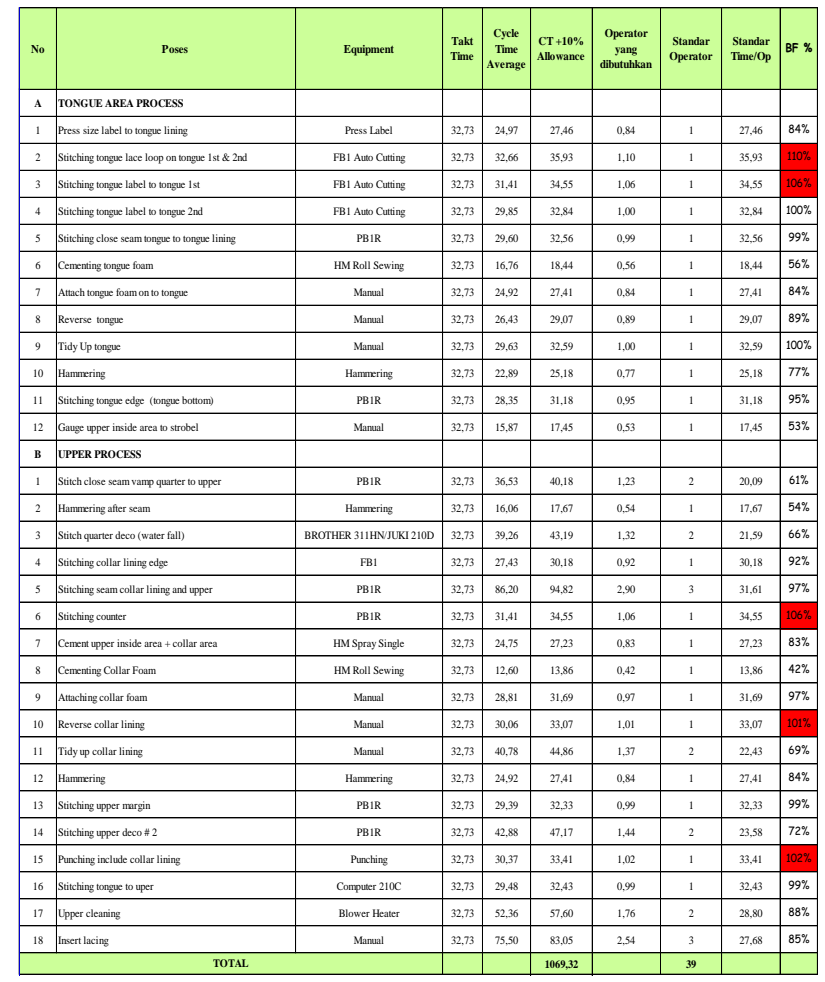

(Sumber: Pengolahan Penelitian, 2019)

\section{Keterangan:}

Berdasarkan pengamatan waktu siklus pada tabel diatas terdapat 5 proses yang mengalami bootleneck/penumpukan atau beban kerja yang lebih.

1. Pada proses size label to tongue lining memiliki rata-rata waktu siklus 24.97 detik dengan kelonggaran $10 \%$ menjadi 27.46 detik,

2. Pada proses stitching tongue lace loop on tongue 1 st\&2nd memiliki rata-rata waktu siklus 32.66 detik dengan kelonggaran 10\%, sehingga waktu siklus menjadi 35.93 detik,

Adapun grafiknya bisa dilihat di bawah ini:

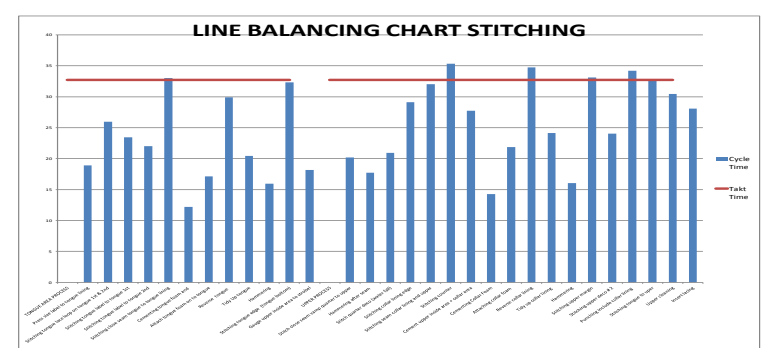

(Sumber: Pengolahan Penelitian, 2019)

Gambar 4.3GrafikLine Balancing Area Stitching Nike Tanjun

Adapun pengamatan waktu siklus area Assembling dapat dilihat pada Tabel $\mathbf{4 . 6}$
Tabel 4.6 Pengamatan Waktu Siklus Area Assy

\begin{tabular}{|c|c|c|c|c|c|c|c|c|c|}
\hline No & DESCRIPTION PROCESS & Equipment & $\begin{array}{l}\text { Takt } \\
\text { Time }\end{array}$ & $\begin{array}{c}\text { Cycle } \\
\text { Time } \\
\text { Average }\end{array}$ & $\begin{array}{l}\mathrm{CT}+10 \% \\
\text { Allowance }\end{array}$ & $\begin{array}{c}\text { Operator } \\
\text { yerang } \\
\text { dibuthankan }\end{array}$ & $\begin{array}{l}\text { Standar } \\
\text { Operator }\end{array}$ & $\begin{array}{l}\text { Standar } \\
\text { Time/op } \\
\text { The }\end{array}$ & BF \% \\
\hline 1 & Back Part Molding (Double Head : I Unit + Single Head: I Unitt) & BCABPM & 16,36 & 22,73 & 25,01 & 1,53 & 2 & 12,50 & $76 \%$ \\
\hline 2 & Put into the back part holder to mintain the shape(Hel Shape Holding) & Manual & 16,36 & & & & & & \\
\hline 3 & Shiching Gathcring Tape & Gathering & 16,36 & 12,23 & 13,46 & 0.82 & 1 & 13,46 & $82 \%$ \\
\hline 4 & Sirmbel stiching + Checking stroble tension & Srrobel & 16,36 & 50,33 & 55,36 & 3,38 & 4 & 13,84 & $85 \%$ \\
\hline 5 & Metal Detector & Necdle Detector & 16,36 & 6,57 & 7,22 & 0,44 & 1 & 7,22 & $44 \%$ \\
\hline 6 & Last preparation & Manual & 16,36 & 10,29 & 11,32 & 0,69 & 1 & 11,32 & $69 \%$ \\
\hline 7 & |inser last to upper + Hammering & Ineert Last & 16,36 & 24,84 & 27,33 & 1,67 & 2 & 13,66 & $84 \%$ \\
\hline 8 & Heel lasting & Heel Last & 16,36 & 23,44 & 25,79 & 1,58 & 2 & 12,89 & $79 \%$ \\
\hline 9 & Trightening hace + insert texon (front area) & Manual & 16,36 & 55,09 & 60,60 & 3,70 & 4 & 15,15 & $93 \%$ \\
\hline 10 & Heat seting & $\begin{array}{ll}\text { Heat Setting } \\
\end{array}$ & & & & & & & \\
\hline 11 & Preparation outsole (Bottom) & Manual & 16,36 & 10,42 & 11,46 & 0,70 & 1 & 11,46 & $70 \%$ \\
\hline 12 & Numbering Outsole & Manual & 16,36 & 10,66 & 11,72 & 0,72 & 1 & 11,72 & $72 \%$ \\
\hline 13 & Gauge marking USE CNC & Gauge Marking & 16,36 & 47,73 & 52,51 & 3,21 & 3 & 17,50 & $107 \%$ \\
\hline 14 & Bottom Primer & Manual & 16,36 & 50,89 & 55,98 & 3,42 & 4 & 13,99 & $86 \%$ \\
\hline 15 & Bottom drying only & Dry Chamber & & & & & & & \\
\hline 16 & Pair natch and move to conveyor & Manual & 16,36 & 15,04 & 16,54 & 1,01 & 1 & 16,54 & $101 \%$ \\
\hline 17 & Upper primmering & Manual & 16,36 & 81,00 & 89,10 & 5,45 & 6 & 14,85 & $91 \%$ \\
\hline 18 & Drying chamber & Dry Chamber & & & & & & & \\
\hline 19 & Upper cemenent & Manual & 16,36 & 79,60 & 87,56 & 5,35 & 6 & 14,59 & $89 \%$ \\
\hline 20 & Bottom cennent (Top Arca) & Manual & 16,36 & 52,31 & 57,54 & 3,52 & 4 & 14,39 & $88 \%$ \\
\hline 21 & Drying chamber & Dry Chamber & & & & & & & \\
\hline 22 & Attaching outsole to upper & Manual & 16,36 & 139,60 & 153,56 & 9,38 & 10 & 15,36 & $94 \%$ \\
\hline 23 & Univeral press (PAd toe spring) & Univeral Press & 16,36 & 48,38 & 53,21 & 3.25 & 4 & 13,30 & $81 \%$ \\
\hline 24 & Chilling Chamber & Chiller Chamber & & & & & & & \\
\hline 25 & Open Lacc+Delasting (Hinge LassLLass patathan) & Manual & 16,36 & 17,09 & 18,79 & 1,15 & 1 & 18,79 & $15 \%$ \\
\hline 26 & Cleaning upper and take plassic & Manual & 16,36 & 25,10 & 27,61 & 1.69 & 2 & 13,80 & $84 \%$ \\
\hline 27 & Cleaning Last & Brushing & 16,36 & 12,02 & 13,23 & 0,81 & 1 & 13,23 & $81 \%$ \\
\hline 28 & Cementing and insert sockliner & Manual & 16,36 & 16,86 & 18,55 & 1,13 & 1 & 18,55 & $13 \%$ \\
\hline 29 & Press Sockliner & \begin{tabular}{l|l|l} 
Press Sockliner \\
\end{tabular} & 16,36 & 21,75 & 23,93 & 1,46 & 2 & \begin{tabular}{|l|l|}
11,96 \\
\end{tabular} & $73 \%$ \\
\hline 30 & Repaired & Manual & 16,36 & 17992 & 19,71 & 1,20 & 1 & \begin{tabular}{|l|}
19,71 \\
\end{tabular} & $1200 \%$ \\
\hline 31 & Molded stuffing paper & Manual & 16,36 & 14,37 & 15,80 & 0.97 & 1 & 15,80 & $97 \%$ \\
\hline 32 & Insert tissue paper & Manual & 16,36 & 11,78 & 12,96 & 0,79 & 1 & 12,96 & $79 \%$ \\
\hline 33 & Reset lace & Manual & 16,36 & 53,73 & 59,10 & 3,61 & 4 & 14,77 & $90 \%$ \\
\hline 34 & Clkaning shoes & Manual & 16,36 & 21,04 & 23,14 & 1,41 & 2 & 11,57 & $71 \%$ \\
\hline 35 & Attaching UPC Label + scan & Manual & 16,36 & \begin{tabular}{l|l|l|l|}
11,38 \\
\end{tabular} & 12,52 & 0,76 & 1 & \begin{tabular}{l|l|l|}
12,52 \\
\end{tabular} & $76 . \%$ \\
\hline 36 & IInner box folding up & Manual & 16,36 & 11,33 & 12,46 & 0,76 & 1 & 12,46 & $76 \%$ \\
\hline 37 & Wrapping paper & $\begin{array}{l}\text { Manual } \\
\end{array}$ & 16,36 & \begin{tabular}{l|l}
10,69 \\
\end{tabular} & 11,76 & 0,72 & 1 & \begin{tabular}{|l|l|}
11,76 \\
\end{tabular} & $72 \%$ \\
\hline 38 & Hang tag & Manual & 16,36 & 14,09 & 15,49 & 0.95 & 1 & \begin{tabular}{|l|l|}
15,49 \\
\end{tabular} & $95 \%$ \\
\hline & TOTAL & & & & 1100,30 & & 77 & & \\
\hline
\end{tabular}

(Sumber: Pengolahan Penelitian, 2019)

Keterangan:

Dapat dilihat bahwa terdapat dua proses yang mengalami penumpukan, sedangkan yang tiga proses memiliki beban kerja yang tinggi. Adapun proses-proses tersebut ialah sebagai berikut:

1.Gauge marking, memiliki rata-rata cycle time 52.51 detik, dengan beban kerja sebesar $107 \%$;

2.Pair mach and move to conveyor, memiliki rata-rata cycle time 16.54 detik, dengan beban kerja sebesar $101 \%$;

3.Open last and delasting, memiliki rata-rata cycle time 18.79 detik, dengan beban kerja sebesar $115 \%$.

4.Cementing and insert sockliner, memiliki ratarata cycle time 18.55 detik, dengan beban kerja sebesar $113 \%$;

5.Repaired, memiliki rata-rata cycle time 19.71 detik, dengan bebean kerja sebesar $120 \%$;

Adapun grafik nya bisa dilihat dibawah ini: 


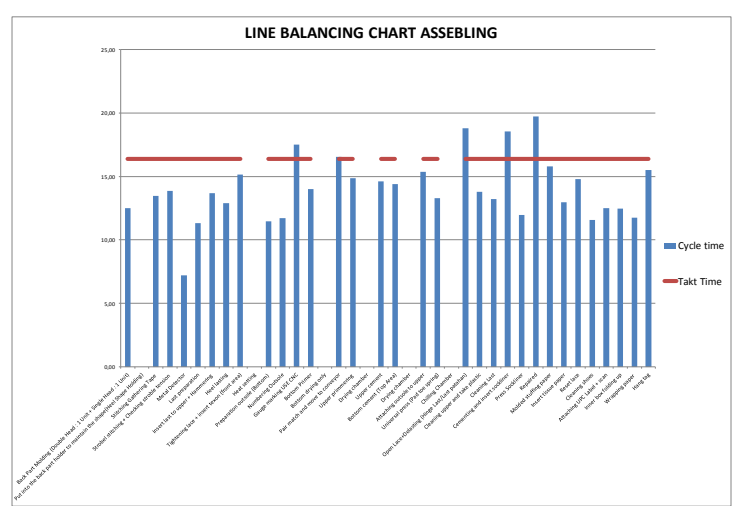

(Sumber: Pengolahan Penelitian, 2019)

Gambar 4.4GrafikLine Balancing Area AssyNike Tanjun

\section{Tindakan Perbaikan}

untuk menyelesaikan masalah-masalah yang diatas, maka paraperusahaan akan melakukan tindakan perbaikan seperti berikut: 1.Perubahan layout;

2. Melakukan perbaikan mesin secara berkala; 3. Mentraining ulang team member.

\section{E. Usulan Layout Baru Plant D5}

Adapun layout baru dapat dilihat pada

Gambar 4. 5 di bawah in

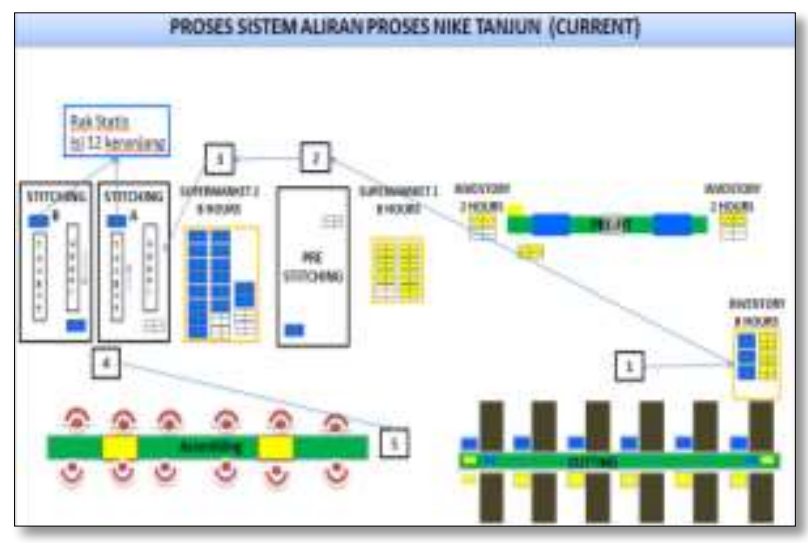

(Sumber: Penolahan Penelitian,2019)

Gambar4.5 Layout baru Nike Tanjun

Dari usulan layout diatas ada perbaikan aliran proses, yang sebelumnya terdapat 7 area kerja, dengan usulam layout baru ini hanya memiliki 5 stasiun kerja. sehingga waktu tunggu untuk proses selanjutnya tidak begitu lama.

\section{F. Simulasi Layout}

Sebelum layout diimplementasikan di produksi line y10, maka semua departemen yang terkait khususnya departemen Industrial Engineering (IE), sebagai penanggung jawab perlu diadakan simulasi layout dan juga simulasi 3P (Prepartion, Production, Process) terlebih dahulu. Di PT. KMK Global Sports sendiri setiap akan melakukan re-layout besar-besaran akan diadakan simulasi layout atau yang sering disebut 3P (Preparation, Production, Process). Tujuan dilakukan simulasi adalah untuk mengetahui masalah apa saja yang terjadi serta meminalisir atau mencegah permasalah tersebut supaya tidak terjadi kembali.

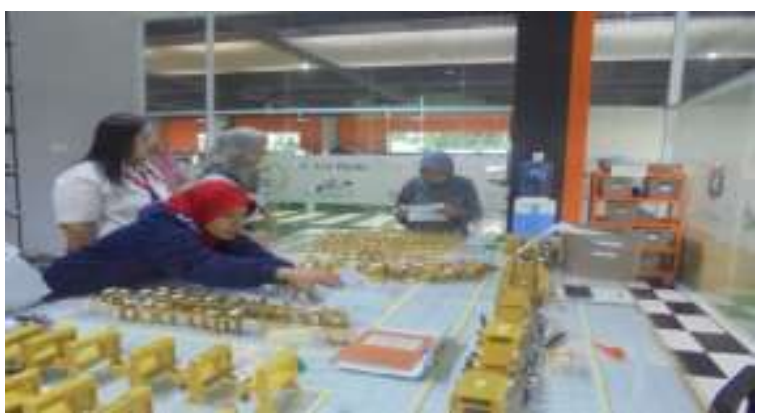

(Sumber: PT. KMK Global Sports , 2019)

Gambar:4.6 Simulasi 3p

\section{G. Standar Work Sheet (SWS)}

Setelah melakukan simulasi layout, maka selanjutnya usulan layout tersebut diterapkan di lini produksi. Setelah layout diterapkan selanjutnya akan mentraining ulang team member dengan cara membuat standar kerja, berbentuk lembaran kerja.

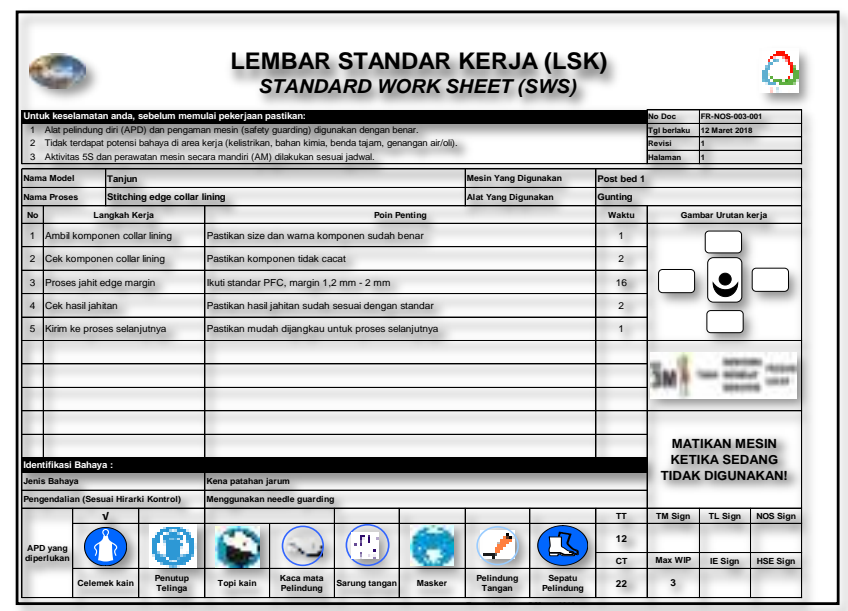

(Sumber: PT. KMK Global sports, 2019)

Gambar 4.7 StandarWork sheetPT. KMK Global

Sports 


\section{H. Hasil Penelitian}

Adapun hasil dari penelitian waktu siklus diatas sebelum dan sesudah melakukan relayout adalah sebagai berikut:

Tabel 4.7 Selisih Waktu Siklus Sesudah dan Sebelum Re-layout.

Tabel 4.7Selisih Waktu SiklusSesudah dan SebelumRe-layot

\begin{tabular}{|c|l|c|c|c|c|}
\hline \multirow{2}{*}{ NO } & \multirow{2}{*}{ Area Proses } & \multicolumn{4}{|c|}{ Total Cycle Time Line balancing (Detik) } \\
\cline { 3 - 6 } & & Sebelum & Sesudah & $\begin{array}{c}\text { Selisih } \\
\text { (detik) }\end{array}$ & $\begin{array}{c}\text { selisih } \\
\%\end{array}$ \\
\hline 1 & Cutting & 97 detik & 97 detik & 0 & $0 \%$ \\
\hline 2 & Pre-fit & 226,08 detik & 213,52 detik & 12,56 & $6 \%$ \\
\hline 3 & Stitching & 1069,32 detik & 944,21 detik & 125,11 & $12 \%$ \\
\hline 4 & Assembling & 1069,32 detik & 1003,68 detik & 65,64 & $6 \%$ \\
\hline & \multirow{2}{*nnyyyy}{ TOTAL } & $\mathbf{2 4 6 1 , 7 2}$ & $\mathbf{2 2 5 8 , 4 1}$ & $\mathbf{2 0 3 , 3 1}$ & $\mathbf{8 \%}$ \\
\hline
\end{tabular}

( Sumber: Pengolahan Penelitian, 2019)

Dari tabel tersebut dapat diliha hasilt perbandingan antara lini produksi awal dan lini produksi setelah melakukan perbaikan yaitu efeisiensi nya meningkat sebesar $8 \%$, dengan waktu tunggu berkurang sebanyak 203.31 detik atau sekitar 3 menit 38 detik. Untuk tabel perbandingan operator sebelum dan sesudah relayout dapat dilihat pada tabel dibawah ini:

Tabel 4.8 Selisih Operator Sesudah dan Sebelum Re-layout

Tabel 4.8 Selisih Operator Sesudah dan Sebelum Relayout

\begin{tabular}{|c|c|c|c|c|c|}
\hline \multirow{2}{*}{ NO } & \multirow{2}{*}{ Area Proses } & \multicolumn{4}{|c|}{ Total Operator } \\
\hline & & Sebelum & Sesudah & Selisih & $\begin{array}{c}\text { selisih } \\
\%\end{array}$ \\
\hline 1 & Cutting & 11 Orang & 11 Orang & 0 & $0 \%$ \\
\hline 2 & Pre-fit & 14 Orang & 14 Orang & 0 & $0 \%$ \\
\hline 3 & Stitching & 39 Orang & 35 Orang & 4 Orang & $10 \%$ \\
\hline 4 & Assembling & 77 Orang & 71 Orang & 6 0rang & $8 \%$ \\
\hline & TOTAL & 141 Orang & 131 Orang & 10 Orang & $7 \%$ \\
\hline
\end{tabular}

(Sumber: Pengolahan Penelitian, 2019)
Dari tabel diatas dapat diketahui bahwa dengan melakukan perubahan layout, Departemen D5 bisa melakukan efisiensi sebsar $7 \%$ dari total operator yang ada, dan untuk hasil produktivitas setelah melakukan relayout dapat dilihat pada tabel berikut:

Tabel 4.9Accumulation Production Plant D5 Line Y10 Setelah Relayout

\begin{tabular}{|c|c|c|c|c|}
\hline \multirow{2}{*}{ BULAN } & \multicolumn{2}{|c|}{$\begin{array}{c}\text { ACCUMULASI PRODUCTION } \\
\text { AFTER RELAYOUT }\end{array}$} & \multirow{2}{*}{$\%$} & \multirow{2}{*}{ Balance } \\
\cline { 2 - 3 } & PLAN & ACTUAL & & -9920 \\
\hline MARET'19 & 38720 & 28800 & $74 \%$ & -1100 \\
\hline APRIL'19 & 38720 & 37620 & $97 \%$ & -500 \\
\hline MEI'19 & 38720 & 38220 & $99 \%$ & $\mathbf{- 1 1 5 2 0}$ \\
\hline TOTAL & $\mathbf{1 1 6 1 6 0}$ & $\mathbf{1 0 4 6 4 0}$ & $\mathbf{9 0 \%}$ & \\
\hline
\end{tabular}

(Sumber: Pengolahan Penelitian, 2019)

\section{Proses Standarisasi}

Setelah melakukan pengamatan cycle time, maka selanjutnya akan dilakukan standarisasi model tersebut, dari mulai jumlah team member (Direct), mesin yang digunakan serta hasil dari pengamatan cycle time dan akan dimasukan ke line balancing sheet.

\section{VKESIMPULAN DAN SARAN}

\section{A. Kesimpulan}

BerdasarkanhasilPenelitianRelayoutFasilitas Produksi di PT. KMK Global Sports sebagaiberikut:

1. Hasil produktivitaskaryawan pada lineHasilproduktivitaskaryawan pada line Y10 di PT. KMK Global Sports mengalamipeningkatanproduktivitas, dari yang

sebelumnyakaryawanmampumenghasilkano utput perjamsebanyak 170 pasang /jam, makadenganadanyaperubahanlayout dan standarisasi proses kerja pada line Y10 Nike Tanjunmengalamipeningkatanproduktivitass ebanyak 215 pasang/jam.

2. Hasil produksidenganpenerapan line balancing

selamatigabulanmengalamipeningkatandari yang

sebelumnyakekuranganproduksiselamatigab 
ulansebanyak 36.800 pasang, menjadi 11.520 pasang. Serta bebankerja yang merata, selainituadabeberapa proses yang digabungkanuntukmeningkatkanefisiensi operator.

setelahmelakukanrelayoutliniproduksi line Y10 mengalamipenurunan lead time atau total waktukeseluruhandari yang sebelumnyamemiliki total waktusebesar 2461.72 detikatau 41,02 menitdengan total pekerjasebanyak 141 orang , menjadi 2258.4 1 atau 37.64 menitdengan total pekerjasebanyak 131 orang.

\section{DAFTAR PUSTAKA}

Angki, Arwin. (2016).Perancangan Ulang Tata Letak Fasilitas Produksi CV. Daya Mandiri Pontianak Menggunakan Metode Systematic Layout Palnning and Craft.

Apple, James M. (1990).Tata Letak Pabrik dan Pemindahan Buku. Institut Teknologi Bandung: Bandung. Assauri, Sofyan.1980. Manajemen Produksi. Lembaga Penerbit FE UI. Jakarta.I

Alfatiyah,

$R$.

(2017).

PerencanaanProduksiMinyakTelonUkuran 100 MIDenganMetode Time Series Di Pt. MerpatiMahardika. Teknik Industri, 9(25).

Bastuti, S., \& Teddy, T. (2017, December). AnalisisPersediaanBarangDenganMetode Time Series Dan Sistem Distribution Requirement Planning UntukMengoptimalkanPermintaanBarang Di Pt. Asri MandiriGemilang. In Proceedings (Vol. 2, No. 1)

Bastuti, S., Alfatiyah, R., Shobur, M., \& Candra, A. (2019). ManajemenLogistik.

Candra, A. (2019). PengendalianPersediaan Material Pada Produksi Hot Mix DenganPendekatanMetode Economic Order Quantity (Eoq). Jitmi (Jurnallmiah Teknik Dan ManajemenIndustri), 1(2), 145153.

Budi, T. S., Supriyadi, E., \& Zulziar, M. (2018). Analisis Konfigurasi Proses Produksi Cokelat Stick Coverture Menggunakan Metode Design Of Experiments (Doe) Di Pt. Gandum Mas Kencana. JITMI (Jurnal Ilmiah Teknik dan Manajemen Industri), 1(1), 87-96.
Barnes, Ralph, M,. (1980).Motion and Time Study Design and Measurement Work. New york: Wiley.

David Setyawan, Stefanus Soegiharto, Jerry Agus. (2012) "Perbaikan Sistem Produksi Dengan Metode Line Balancing Pada Perusahaan Pembuat Mesin Pertanian PT. Agrindo Di Gresik."Jurnal Jurusan Teknik Industri Universitas Surabaya.

Emalia, Atriantatri. (2016).Perancangan Ulang Tata Letak Fasilitas Produksi Guna Meminimumkan Jarak dan Biaya Material Handling Menggunakan Aplikasi Quantitatif System Version 3.0 Pada PT. Industri Sandang Nusantara Unit Patal Grati Pasuruan.

Gaspersz, Vincent. (2001).Production Planning and Inventory Control, Berdasarkan Sistem Terintegrasi MRP II dan JIT Menuju Manufakturing. Penerbit: Gramedia Pustaka Utama. Jakarta.

Hiregoudar, Chandrasekar. (2007).Facility Planning \& Layout Design, India: Technical Publication Pune.

Herawati. (2014).Analisis Layout Dan Line Balancing Fasilitas Produksi. Fakultas Ekonomi. Universitas Nusantara PGRI Kediri.

Husni Mubarok Lukmandono. (2015).Perancangan Ulang Tata Letak Fasilitas Dengan Pendekatan Metode Systematic Layout Planning Guna Meningkatkan Produktivitas Di CV. Putra Perkasa.

Heizer, Jay, dan Barry Render. 2014. ManajemenOperasi. EdisiKesebelas. Terjemahan oleh KurniaHirson, dkk. 2015. Jakarta: SalembaEmpat.

Kurnia, D., Bastuti, S., \&Istiqomah, B. N. (2018). AnalisisPengendalianBahan Baku Pada Produk Tas DenganMenggunakanMetode Material Requirements Planning (Mrp) UntukMeminimalkanBiayaPenyimpanan Di Home Industry Amel Collection. Jitmi (Jurnalllmiah Teknik Dan ManajemenIndustri), 1(1), 22-28. 
Lestari, Dian Suci. (2016). Usulan Perbaikan Sistem Produksi Pada Proses Core CT/VT Tipe VT1-24-1 Dengan Metode Line Balancing Untuk Meminimalisi Bottleneck Di PT. Trafoindo Prima Perkasa.Institut Teknologi Indonesia, Serpong.

Mustofa Coir, Dodi Sofyan Arif, \& Mery Riska. (2016).Desain Ulang Tata Letak Produksi menggunakan Metode Systematic Layout Planning Pada Pabrik Kelapa Sawit Sungai Pagar.

Nurhasanah, Nunung. (2012).Pengukuran Produktivitas Alur Produksi Menggunakan Metode Line BalancingDi PD. Sandang Jaya. Universitas Al azhar Indonesia.

Rionaldo Yuliant, Alex Saleh \& Abu Bakar (2015). Perancangan Tata Letak Fasilitas Perusahaan Garmen CV. X Dengan Menggunakan Metode Konvensional.

Risma A, S,. \& Dian, H,. (2012).Usulan Perbaikan Metode Kerja Berdasarkan Micromotion Study Dan Penerapan Metode 5S Untuk Meningkatkan Produktifitas. Jurnal Teknologi, Institut Sains \& Teknologi AKPRIND Yogyakarta Volume. 1 Nomor 2, Desember 2008, 191-203.

Syahrul Ramadhan A211-08-293. (2012).Analisis Penerapan Konsep Penyeimbangan Lini (Line Balancing) pada Sistem Produksi Percetakan Harian Tribun Timur di Makassar". Jurnal Jurusan Manajemen Fakultas Ekonomi dan Bisnis Universitas Hasanuddin Makassar.

Sila, S,. (2012).Usulan Perbaikan Tata Letak Produksi Keripik Kentang Di Industri Kecil Menengah Bencok 26 Proposed Improvement of Potato Chips Production Layout In Small And Medium Industries Bencok 26.Tugas Akhir, Jurusan Teknik Industri, Fakultas Teknologi Industri, Universitas Gunadarma.
Sedarmayanti,. (2009).Tata Kerja dan Produktivitas Kerja. Penerbit: Mandar Maju, Bandung.

Sawyer, J. H. F,. (1970).Line Balancing. London: The Machinery Publishing CO. LTD.

Shannon, Robet E. (1975)Engineering Management. Universitas Indonesia.

Sutalaksana, I (2006).Teknik Perancangan Sistem Kerja, Institut Teknologi Bandung.

Wignjosoebroto, S. (1993).Pengantar Teknik Industri. Penerbit Prima Printing, Surabaya.

Wignjosoebroto, S. (2009). Tata Letak Pabrik dan Pemindahan Bahan.Edisi ketiga. Penerbit: Widya Guna, Surbaya.

Aiello, S.,Ohara, A. \& Saing, S. (2007).Systematic Layout Plant For Baystate Benefit Service, Northeastern University Spring, WWW.baystatebenefit.com

Emsoff, (1970). Corporate Social Responsibility.https://media.neliti.com. 